\title{
Dimmable LED Drivers Operating in Discontinuous Conduction Mode
}

\author{
Olegs Tetervenoks (Doctoral student, Riga Technical University), \\ Irena Milashevski (Doctoral student, Tallinn University of Technology)
}

\begin{abstract}
For the modern smart lighting systems one of the most attractive LED advantages is the dimming possibility. Many researchers and engineers from the field of lighting engineering are trying to find compromise between the efficiency of LED dimming process and the ease of its implementation. This paper also presents an attempt to improve LED dimmer parameters. Comparative investigation of the operation of buck LED drivers in continuous conduction mode and discontinuous conduction mode are discussed here. The first section of paper briefly describes the controllability parameters of the converter in both of these modes. The positive impact of discontinuous conduction mode on the controllability parameters as well as the results of the analytical estimation and the results of associated experiments are summarized at the end of the first section. The second section describes the impact of discontinuous conduction mode on the losses of LED dimmer. The analytical estimation of power losses in the main converter components for both operation modes as well as the summary of the experiments to identify distribution of power losses between these components are presented in this section. Finally, the conclusions about using discontinuous conduction mode for dimmable LED lamps as well as guidelines for the choosing of the components with the most appropriate parameters are drawn.
\end{abstract}

Keywords - Lighting, LED lamps, controllability, electrical ballasts, DC-DC power converters.

\section{INTRODUCTION}

At the given time growing demand for electrical energy and limited facilities of its generation asks for lower energy consumption of electrical equipment. This can be done through the increase of the efficiency and avoidance of unnecessary operation - making the equipment "smart" [1], [2]. In the field of lighting utilization of these two ways can be combined with utilization of Light Emitting Diodes (LEDs). On the one hand modern LEDs have efficacy of more than hundred lumens per watt [3], but on the other - it is possible to adjust the light produced by LEDs with no negative impact on them.

Amount of light produced by LEDs is proportional to their current. This brings forward two light regulation methods: fluent and pulse mode light regulation. Since the light produced by LEDs follows their current at a very high rate [4], [5] the second method may lead to flickering and stroboscopic effects. Another light regulation method is possible because LEDs are rather low power elements and an LED luminary usually includes a number of LEDs. It is possible to divide them into groups and control each group separately. Taking into account drawbacks and benefits of the methods, the first one (fluent) is preferable.
The fluent mode light regulation can be provided by a dedicated circuit called electronic LED ballast that forms the output current in correspondence with the control command. There are many kinds of the electronic ballasts, but the most efficient of them are made as switch mode power supplies with $\mathrm{AC}$ or DC input. In the case of DC input various DC choppers can be used as the fluent light regulators: buck, boost, buck-boost [6] and Cuk [7]. The above mentioned papers do not pay special attention to operation of these converters in the discontinuous (DCM) or continuous conduction mode (CCM). At the same time some other researches apply DCM to solve grid interfacing problems [8] or to reduce size of LED drivers [9] (mostly in high input voltage applications).

There are several criteria of adaptability of different electronic circuits as LED drivers. Previously authors have estimated the most common DC/DC converters from the point of view of their controllability [10], efficiency [11] and weight/size [12]. The mentioned papers are mostly focused on CCM operation of these converters. This paper compares the operation of buck LED drivers both in CCM and DCM.

The following aims of this research can be emphasized: 1) to determine the controllability parameters of the converter in DCM mode and to compare them with those in CCM; 2) to find the impact of the conduction mode on the losses and efficiency; 3) to estimate the volume and weight of the converter operated in DCM; 4) to find the reasons of positive differences of DCM operation in order to apply them to other LED drivers; 5) to identify possible drawbacks of the approach and find means how to solve them.

\section{CONTROLLABILITY IN DCM AND CCM}

The controllability of LED drivers is understood as a set of parameters of these drivers that reflects their capability to control lighting parameters. The parameters of controllability are important in the context of a closed loop system that consists of a regulator and LED lamp. The last one, in turn, includes an LED driver and LED matrix.

In the given research a DC/DC buck converter is used as an LED driver. It can operate either in continuous or discontinuous operation mode. The converter operates in discontinuous mode when low current is drawn by the load, and in continuous mode at higher load current. There is also a boundary point between CCM and DCM when the inductor current falls to zero exactly at the end of the commutation cycle. 
The generalized idea of this research is to move the boundary line between CCM and DCM so that V-A curve of LEDs is mostly located in DCM operation region of the driver. It is expected that the output voltage of the driver increases in DCM which leads to the need to reduce duty cycle for the same value of the output voltage and current that, in turn, will make the span of duty cycles wider and control of the drivereasier (Fig.1). The operation of the driver in CCM is shown in Fig.1(a). Then the operation points of the lamp are defined by horizontal CCM lines, but range of the duty cycle values of the driver is narrow (from $76 \%$ to $93 \%$ ). In contrast, Fig.1(b) reflects the operation of the driver in DCM. Then the same values of the voltage and current are achieved at lower values of the duty cycle, but its range is wider (from $12 \%$ to $79 \%$ ).

\section{A. Parameters of Controllability}

The following parameters are used as criteria of evaluation of control performance: 1) maximal gain of the lamp; 2) ratio of its maximum and minimum; 3) nonlinearity of regulation and 3) span of practically usable values of duty cycle.

The first parameter is the rate of changes of Relative Output $(R O)$ with the corresponding changes of duty cycle $D$, where $R O$ is defined as a ratio of regulated parameter (luminous flux, illuminance, current etc.) to its maximal value expressed in percents. In generalized form the gain can be found as a derivative of $R O$ with respect to $D$ and is also function of $D$ :

$$
G_{L E D}=f(D)=\frac{d R O}{d D} \approx \frac{\Delta R O_{k}}{\Delta D_{k}},
$$

In (1) $\triangle R O$ and $\triangle D$ are finite changes of $R O$ and $D$ in the k-th point. In this paper $R O$ is relative current related to the base $3000 \mathrm{~mA}$ for simplicity reasons. The ratio of maximal and minimal values of the gain forms the dynamic range:

$$
R G_{L E D}=\frac{G_{L E D \max }}{G_{L E D \min }},
$$

that express also gain changes of the regulation system. In (2)

$$
\begin{gathered}
G_{L E D \max }=\Delta R O_{@ \max } / \Delta D_{@ \max } \text { and } \\
G_{L E D \min }=\Delta R O_{@ \min } / \Delta D_{@ \min },
\end{gathered}
$$

where $\Delta R O_{@ \max }$ and $\Delta R O_{@ \text { min }}$ are changes of the relative output achieved at the corresponding values of the duty cycle $\Delta D_{@ \max }$ and $\Delta D_{@ \min }$ that produces the maximum and minimum.

The nonlinearity $N L$ is a root-mean declination $\Delta S$ of regulation curve $R O(D)$ from the equivalent linear one $R O_{L}(D)$ related to the root-mean value of the curve $S$ :

$$
N L=\frac{\Delta S}{S} \cdot 100 \%,
$$

where $\Delta S$ is defined as:

$$
\Delta S=\sqrt{\frac{1}{D_{\max }-D_{\min }} \int_{D_{\min }}^{D_{\max }}\left[R O(D)-R O_{L}(D)\right]^{2} d D,}
$$

but $\mathrm{S}-$ as

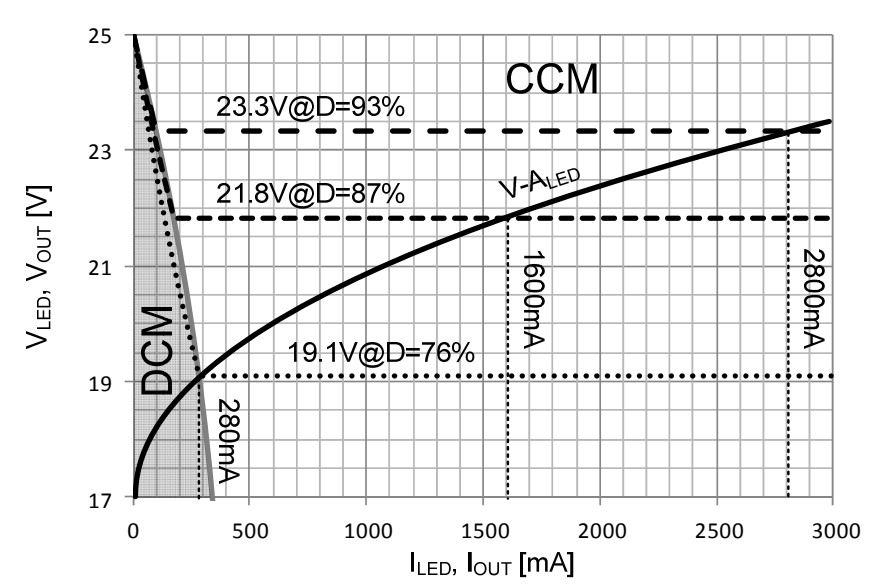

(a)

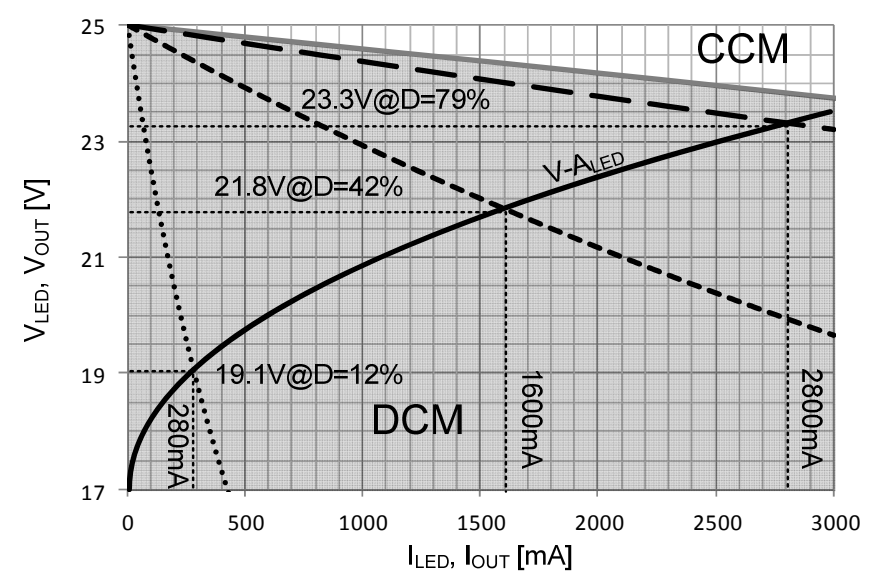

(b)

Fig.1. Calculated operation V-A curves of buck LED driver $\left(\mathrm{V}_{\mathrm{IN}}=25 \mathrm{~V}\right.$, load $7 \mathrm{xW} 724 \mathrm{C} 23.2 \mathrm{~V} \times 2.8 \mathrm{~A} \approx 70 \mathrm{~W}$ ): (a) completely in CCM; (b) completely in DCM.

$$
S=\sqrt{\frac{1}{D_{\max }-D_{\min }} \int_{D_{\min }}^{D_{\max }} R O^{2}(D) d D .}
$$

The last estimated parameter is a ratio of achievable span of relative output vs. span of usable values of duty (average gain) cycle showing how complete is the utilization of control hardware. It is found as the following ratio:

$$
G_{a}=\frac{R O_{\max }-R O_{\min }}{D_{\max }-D_{\min }},
$$

where $D_{\min }$ and $D_{\max }$ are the values of duty cycle that provides the maximal $R O_{\max }$ and minimal $R O_{\min }$ values of $R O$ (when it is assumed that the curve has no extremums).

\section{B. Mathematical Model and Simulation of Buck LED Driver}

Since the discussed LED lamp consists of an LED driver and LED matrix its static mathematical model contains two equations: of the driver and of the matrix.

Well known equations for buck converter can be found from learning literature [13], [14]. For CCM it is:

$$
V_{\text {LEDccm }}=V_{I N} \times D,
$$

but for DCM the following: 


$$
V_{L E D d c m}=V_{I N} \cdot \frac{D^{2}}{I_{L E D} / 4 I_{o b m}+D^{2}},
$$

where $V_{L E D C c m}$ and $V_{L E D c c m}$ are the output voltages of the converter (voltage across LEDs) in CCM and DCM accordingly, $V_{I N}$ is the input voltage of the converter, $I_{L E D}$ is the current of LEDs, $I_{o b m}$ is the boundary of output current between CCM and DCM operation.

Finding the approximated expression of V-A curve of the LED matrix ( 7 in series connected LEDs W724C made by Seoul Semiconductors) is necessary because its analytical expression does not exist, but it is given as a graph in the datasheet. Below the 3rd order polynomial approximation of LED V-A curve is given:

$$
\begin{gathered}
I_{L E D}=f\left(V_{L E D}\right)=a_{0}+a_{1} \cdot\left(V_{L E D}-V_{0}\right)+\ldots \\
\ldots+a_{2} \cdot\left(V_{L E D}-V_{0}\right)^{2}+a_{3} \cdot\left(V_{L E D}-V_{0}\right)^{3}
\end{gathered}
$$

In (11) $\mathrm{V}_{0}=20.2 \mathrm{~V}$ is the working point of the matrix, but $a_{0}$, $a_{1}, a_{2}$ and $a_{3}$ are the polynomial coefficients for the explored LEDs in the range from $17 \mathrm{~V}$ to $23.5 \mathrm{~V}$ and from $0 \mathrm{~mA}$ to $3000 \mathrm{~mA}$. The polynomial coefficients for the described working point are: $a_{0}=557, a_{1}=442, a_{2}=89.6$ and $a_{3}=1.92$.

Since this research is mostly focused on DCM, but analytical solution of (10) and (11) is quite complicated it was decided to do the initial testing through simulation. In order to do that a PSpice model of the lamp has been composed and simulation was done.

The regulation curves of the simulated LED lamp at different values of the inductance are presented in Fig.2. As it is can be concluded from this picture the proposed idea of DCM utilization for better controllability seems quite realistic. The lower is the inductance the wider and better regulation can be achieved. This is also confirmed by data from Table I. The smaller is the dynamic range $R G$, the more stable system performs in whole regulation range. Ratio of achievable span $G_{a}$ shows the utilization of control parameter (duty cycle): the control parameter is utilized better if $G_{a}$ is closer to unity. In accordance with these considerations and data from Table I $1 \mu \mathrm{H}$ inductance provide better regulation performance.

Since the initial simulation showed the validity of the principle itself it has been decided to check it experimentally.

\section{Experiments and Analysis}

A series of experiments have been conducted in order to verify the previously listed assumptions and simulation results. A buck converter with $25 \mathrm{~V}$ on its input intended for a $70 \mathrm{~W}$ LED load has been assembled (in particular the load contains 7 W724C LED of total power $23.2 \mathrm{~V} \times 2.8 \mathrm{~A} \approx$ $70 \mathrm{~W})$. The converter has been tested with different values of inductance $(1,2,4,10,50$ and $250 \mu \mathrm{H})$. The corresponding regulation curves are given in Fig.3, but measured parameters of controllability of LED lamp are listed in Table II. Fig. 3 as well as Table II shows good correspondence of simulated and measured results that also confirm the proposed idea. However the better regulation performance practically appears at $2 \mu \mathrm{H}$ inductance as well as there is larger difference in nonlinearity. These differences can be explained by too idealized model.

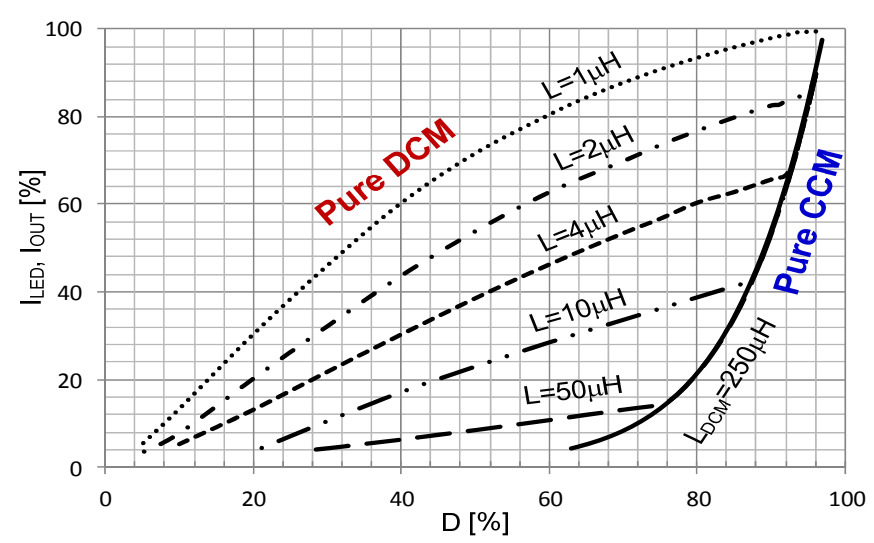

Fig.2. Simulated regulation curves of LED lamp taken in CCM and DCM.

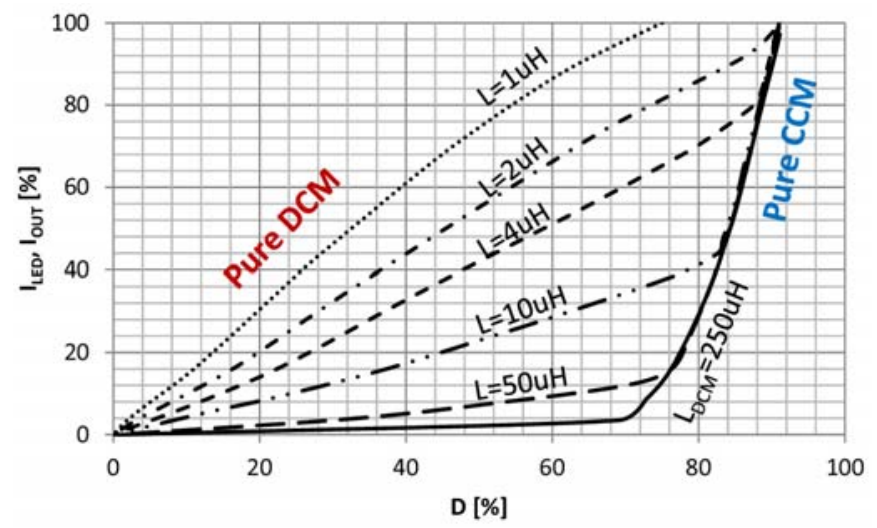

Fig.3. Measured regulation curves of LED lamp taken in CCM and DCM.

TABLE I

SIMULATED PARAMETERS OF CONTROLLABILITY OF LED LAMP

\begin{tabular}{|c|c|c|c|c|c|}
\hline $\mathbf{L}, \boldsymbol{\mu H}$ & $\mathbf{G}_{\text {LEDmin }}$ & $\mathbf{G}_{\text {LEDmax }}$ & $\mathbf{R G}$ & $\mathbf{N L}, \mathbf{\%}$ & $\mathbf{G}_{\mathbf{a}}$ \\
\hline $\mathbf{1}$ & $\mathbf{0 . 5 3}$ & $\mathbf{1 . 6 1}$ & $\mathbf{3 . 0 3}$ & $\mathbf{1 3 . 2}$ & $\mathbf{1 . 1 5}$ \\
\hline 2 & 0.66 & 5.37 & 8.14 & 6.48 & 0.94 \\
\hline 4 & 0.73 & 5.37 & 7.36 & 2.10 & 0.77 \\
\hline 10 & 0.51 & 5.37 & 10.53 & 0.44 & 0.53 \\
\hline 50 & 0.22 & 5.37 & 24.41 & 0.46 & 0.23 \\
\hline 250 & 1.20 & 5.37 & 4.48 & 17.7 & 2.97 \\
\hline
\end{tabular}

TABLE II

MEASURED PARAMETERS OF CONTROLLABILITY OF LED LAMP

\begin{tabular}{|c|c|c|c|c|c|}
\hline $\mathbf{L}, \boldsymbol{\mu H}$ & $\mathbf{G}_{\text {LEDmin }}$ & $\mathbf{G}_{\text {LEDmax }}$ & $\mathbf{R G}$ & $\mathbf{N L}, \mathbf{\%}$ & $\mathbf{G}_{\mathbf{a}}$ \\
\hline 1 & 0.74 & 1.66 & 2.24 & 8.1 & 1.32 \\
\hline $\mathbf{2}$ & $\mathbf{0 . 9 2}$ & $\mathbf{1 . 2 5}$ & $\mathbf{1 . 3 6}$ & $\mathbf{1 . 9}$ & $\mathbf{1 . 1 0}$ \\
\hline 4 & 0.74 & 7.26 & 9.81 & 5.2 & 0.94 \\
\hline 10 & 0.45 & 7.26 & 16.13 & 3.2 & 0.5 \\
\hline 50 & 0.24 & 7.26 & 30.25 & 1.8 & 0.20 \\
\hline 250 & 2.11 & 7.26 & 2.79 & 19.6 & 4.49 \\
\hline
\end{tabular}

\section{LOSSES IN DCM AND CCM}

Another significant question is the impact of DCM on the losses. Analytical estimation of power losses in CCM and DCM as well as the results of the experiments for both operation modes are discussed below. 


\section{A. Analytical Estimation of Losses}

Power losses of the converter are distributed between the main elements of the converter. The analysis of voltage and current curves at steady-state and transient conditions in those elements allows making estimation of distribution of power losses. The main components of the buck converter are two switches (transistor and freewheeling diode), inductor and input and output capacitors. The analytical estimation of losses in this section was made for the components and at the frequency used in the experiments.

The assessment of power losses in CCM in switches of buck converter is discussed in details in [12], so only the results of this estimation at $50 \mathrm{kHz}$ switching frequency and taking into account the parameters of the load (11) are presented in Fig.4(a) and (c).

The estimation of power losses in DCM in switches was conducted in a similar way - Fig. 4(b) and (d). It is worth to mention that in DCM there are no switching losses in diode as well as turn-on losses in transistor as there is no current flowing through the diode at the end of switching period.

The analytical estimation of power losses in the switches shows that the operation of these devices is more efficient in DCM (Fig.4).

Particular attention should be paid to the power losses of the inductor. Inductor power losses usually are divided in two parts: core loss and copper loss (losses in the copper wires).

The major losses of any core material are the hysteresis loss and the eddy current loss. The hysteresis losses $\Delta P_{h}$ can be found from

$$
\Delta P_{h}=\kappa_{h} \cdot v \cdot f \cdot B_{\max }^{2} .
$$

The eddy current losses $\Delta P_{e}$ are equal to

$$
\Delta P_{e}=\kappa_{e} \cdot v \cdot f^{2} \cdot B_{\max }^{2},
$$

where $k_{h}$ and $k_{e}$ are the hysteresis and eddy current loss constants respectively (specified in core datasheet), $v$ is the volume of the core, $f$ is the switching frequency, and $B_{\max }$ is maximum flux density that can be found from

$$
B_{\max }=\frac{V_{L \max } \cdot D}{2 \cdot T \cdot A_{c} \cdot N} \text { or } B_{\max }=\frac{L \cdot \Delta i}{2 \cdot A_{c} \cdot N}
$$

where $V_{\text {Lmax }}$ is the peak voltage across the coil during transistor conduction state, $D$ is duty cycle of control signal of the MOSFET, $T$ is the switching period of the converter, $A_{c}$ is the cross-section area of the inductor core, $N$ is the number of turns, $\Delta i$ is the current ripple in the inductor [15], [16].

It is seen from (12) and (13) that core losses has square dependency from maximum flux density. From (14) it can be concluded that maximum flux density in general may be reduced by using core material with smaller permeability (the core that requires more turns $N$ to get the same inductance $L$ value at the same cross-section area $A_{c}$ and volume of the material $v$ ) and higher resistance of material (prevents eddy currents). Of course hysteresis losses $k_{h}$ should also be taken into account for estimation.

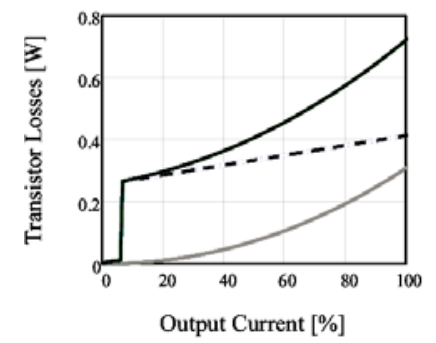

(a)

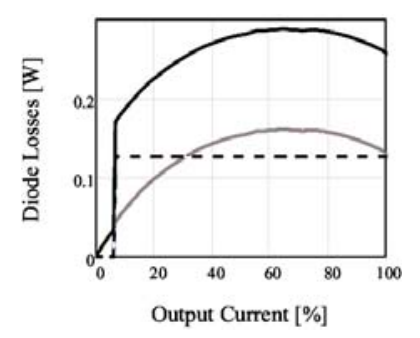

(c)

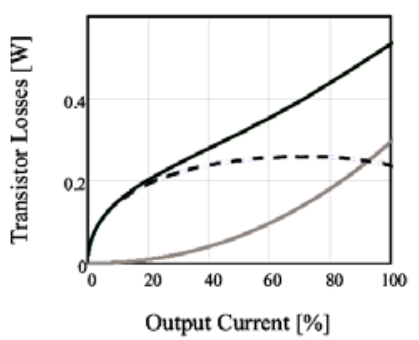

(b)

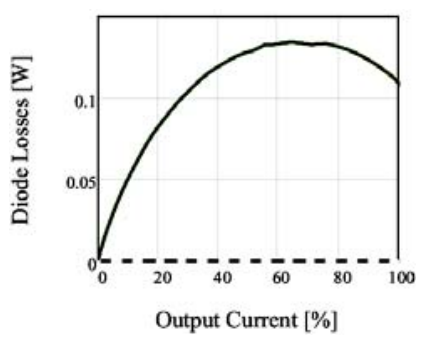

(d)
Fig.4. Power losses in converter switches (gray - conduction loss, dashed switching loss, solid black - total losses): (a) transistor losses in pure CCM $(\mathrm{L}=250 \mu \mathrm{H})$; (b) transistor losses in pure DCM $(\mathrm{L}=1 \mu \mathrm{H})$; (c) diode losses in pure CCM $(\mathrm{L}=250 \mu \mathrm{H}) ;(\mathrm{d})$ diode losses in pure DCM $(\mathrm{L}=1 \mu \mathrm{H})$.

The copper losses of the inductor are associated with the resistance of conducting wire. Alternating current leads to the effects (i.e. skin effect) that decrease conductor area where the current flows (increases conductor resistance). The depth $d_{\text {skin }}$ to which current exists can be found from:

$$
d_{\text {skin }}=\sqrt{\frac{\rho}{\pi \cdot \mu \cdot f}},
$$

where $\rho$ is specific electrical resistance of the conductor material $\left(1.68 \cdot 10^{-8} \Omega \cdot \mathrm{m}\right.$ for the copper) and $\mu$ is the permeability of the conductor $\left(\mu=\mu_{0} \cdot \mu_{R}\right.$, where $\left.\mu_{R} \approx 1\right)$. Therefore the resistance may be divided in two parts: the resistance for direct current $R_{D C}$ and the resistance for alternating current $R_{A C}$ :

$$
\begin{gathered}
R_{D C}=\frac{\rho \cdot l_{w}}{\pi \cdot r_{w}^{2}}, \\
R_{A C}=\frac{\rho \cdot l_{w}}{\pi \cdot d_{\text {skin }} \cdot\left(2 r_{w}-d_{\text {skin }}\right)},
\end{gathered}
$$

where $l_{w}$ is the length of the wire and $r_{w}$ is the radius of the wire [17]. It is worth to mention that $R_{A C}$ applies only for $\mathrm{AC}$ component, so the power losses in the inductor wires are equal to the square of DC current component multiplied by the resistance $R_{D C}$ plus squire of the root-mean square AC current component multiplied by the resistance $R_{A C}$.

For buck converter the power losses in output capacitor depend on its equivalent series resistance $R_{E S R}$ and current ripple in inductor $\Delta i$. In this case power losses are equal to the multiplication of root-mean square (RMS) AC current flowing through the capacitor with equivalent series resistance $R_{E S R}$. In case of pure CCM root-mean square value of AC current flowing through capacitor is equal to the inductor ripple current $\Delta i$ divided by four. In the case of pure DCM it is the difference between RMS of ripple current and output current. 


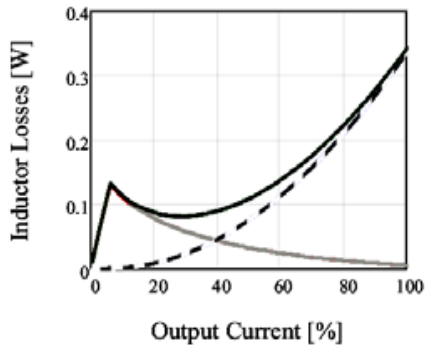

(a)

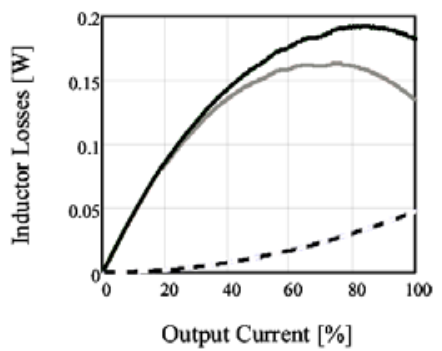

(c)

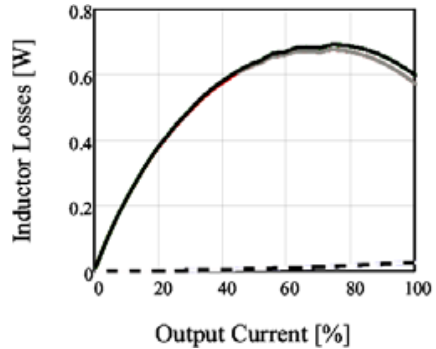

(b)

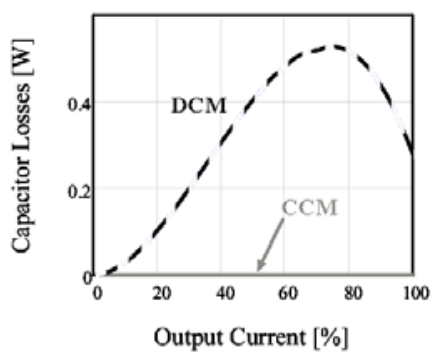

(d)
Fig.5. Power losses in the inductor and output capacitor, where in (a), (b) and (c) solid gray - core loss, dashed black - copper loss, solid black - total losses: (a) inductor losses in $\mathrm{CCM}(\mathrm{L}=250 \mu \mathrm{H}$, core material 26); (b) inductor losses in DCM $(\mathrm{L}=2 \mu \mathrm{H}$, core material 26); (c) inductor losses in DCM $(\mathrm{L}=2 \mu \mathrm{H}$, core material 1); (d) capacitor losses (gray-CCM, dashed $-\mathrm{DCM}$ ).

All the considerations about the inductor losses and output capacitor discussed above are summarized in (Fig.5). It is seen from Fig.5(a) and (b) that in CCM particular attention should be paid to the copper losses, while in DCM losses mainly appears in inductor core - Fig.5(b) and (c). Therefore the main object to focus on is the core material. From (12) and (13) it can be concluded that the volume of the core should be kept as small as possible to decrease core losses.

The power losses of output capacitor in CCM are negligible, while in DCM equivalent series resistance $R_{E S R}$ plays significant role in DCM - Fig.5(d).

The parameters of the components (list in Table III) from experiments were also used for the analytical estimation.

\section{B. Review of Experimental Data}

A series of experiments were conducted to test analytical calculations. The configuration of the test bench as well as the LED lamp, the prototype of the converter and the inductors involved in experiments are shown in Fig.6. As can be seen from Fig.3 pure DCM operation of converter can be practically achieved at $2 \mu \mathrm{H}$ inductance, therefore $250 \mu \mathrm{H}$ and $2 \mu \mathrm{H}$ inductances were selected for practical measurements in pure CCM and pure DCM operation accordingly.

TABLE III

COMPONENTS UTILIZED IN EXPERIMENTS

\begin{tabular}{|c|c|c|c|}
\hline Comp. & Manufacturer & Part \# & Main Parameters \\
\hline Transistor & NXP Semicon. & IRF540N & $\mathrm{V}_{\mathrm{DS}}=100 \mathrm{~V}, \mathrm{R}_{\mathrm{DS}}=77 \mathrm{~m} \Omega$ \\
\hline Diode & ON Semicon & MUR860 & $\mathrm{V}_{\mathrm{RR}}=600 \mathrm{~V}, \mathrm{~V}_{\mathrm{F}}=1.2 \mathrm{~V}$ \\
\hline Output capacitor & Nichicon & $\begin{array}{c}\text { UPW1J47 } \\
1 \mathrm{MHD}\end{array}$ & $\mathrm{C}=470 \mathrm{uF}, \mathrm{R}_{\mathrm{ESR}}=0.13 \Omega$ \\
\hline Inductor Core 1 & Micrometals & $\mathrm{T} 60-26$ & Size $\mathrm{T} 60, \mu_{0}=75$ \\
\hline Inductor Core 2 & Micrometals & $\mathrm{T} 80-26$ & Size T80, $\mu_{0}=75$ \\
\hline Inductor Core 3 & Micrometals & $\mathrm{T} 80-1$ & Size T80, $\mu_{0}=20$ \\
\hline
\end{tabular}

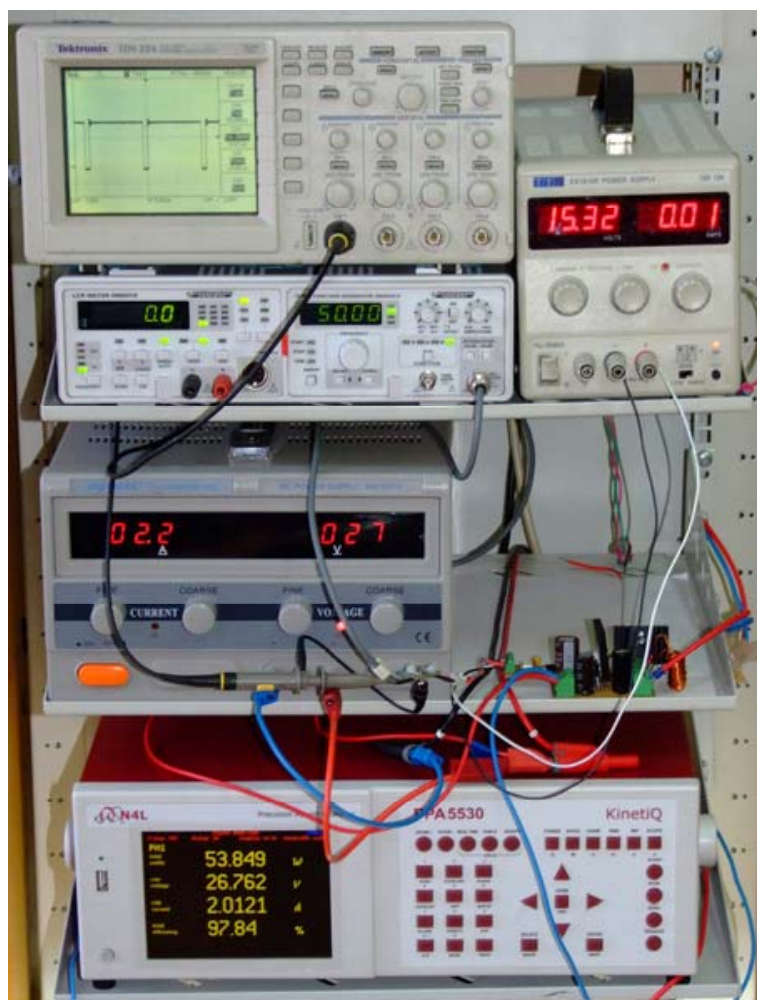

(a)

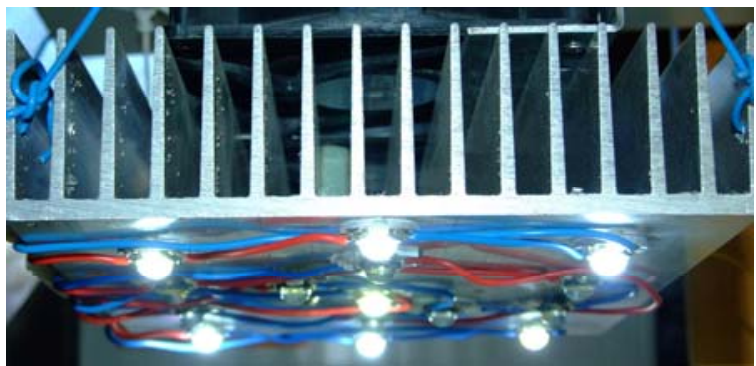

(b)

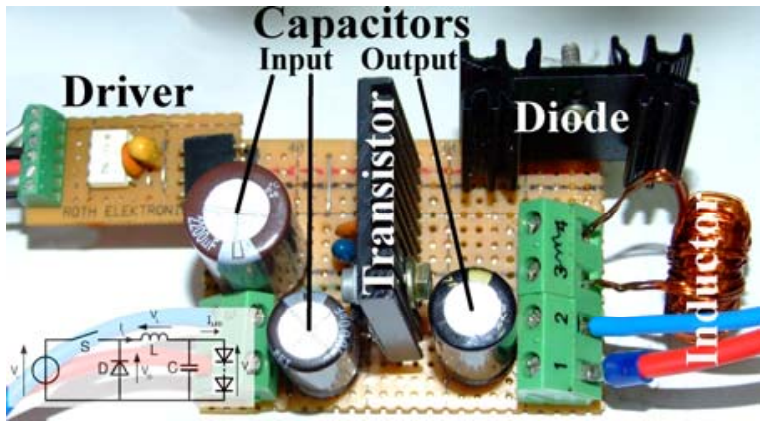

(c)

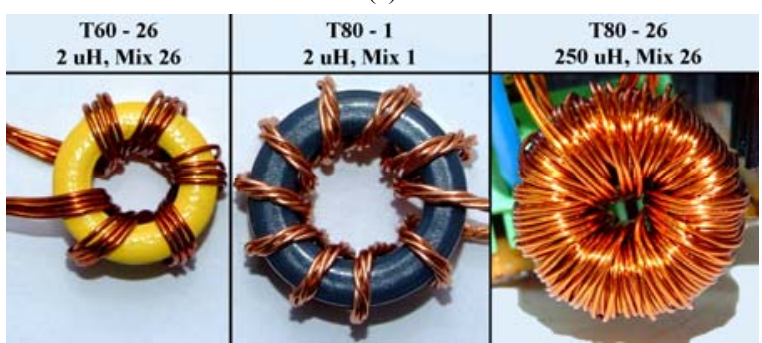

(d)

Fig.6. Equipment involved in the experiments: (a) configuration of the test bench; (b) LED lamp; (c) converter prototype; (d) inductors involved in measurements of the efficiency and losses. 
One of the most difficult parts of these experiments was the distribution of power losses between components.

It was decided to approximately estimate these losses by the difference $\Delta T$ between the ambient temperature $T_{a}$ and temperature of each component using thermal camera.

Thermal image of the converter operating in DCM at full output power is shown in Fig 7. For approximate estimation of power losses the curves that represent dependency between component temperature and dissipated power were measured (Fig.8). They were made by applying known power to the components and then measuring their temperature.

The next step of this experiment was the analysis of thermal images of the converter at different operation modes and output powers. The results of this analysis are summarized in Table IV. In this table total losses are measured using N4L PPA5530 precision power analyzer $(0.03 \%$ accuracy of basic power reading).

Table IV shows a good accordance with theoretical estimation (Fig.4 and Fig.5) except the transistor losses which theoretically in DCM are smaller. Such a difference can be explained with the inexactness of the transistor model.

Table IV shows that the distribution of losses among the components in CCM is quite uniform in the whole output current range. In DCM the inductor is the main source of losses which can be reduced by a proper choice of the core material.

The measured power losses of the converter at different operation modes and output powers are summarized in Fig.9, as well as the overall efficiency of the converter is shown in Fig.10. It can be concluded from these curves that overall efficiency of the converter is higher in CCM, however the efficiency in DCM also can be improved by proper choice of the inductor size and core material, as well as output capacitor.

\section{CONCLUSIONS}

In this paper the operation of LED drivers in DCM have been discussed. The results of simulation and experiments gave opportunity to compare the controllability of LED buck driver with different values of inductance. Obviously, smaller inductance leads to DCM. In this mode the current and duty cycle spans are more equal, therefore the dynamic range is better (closer to 1$)$.

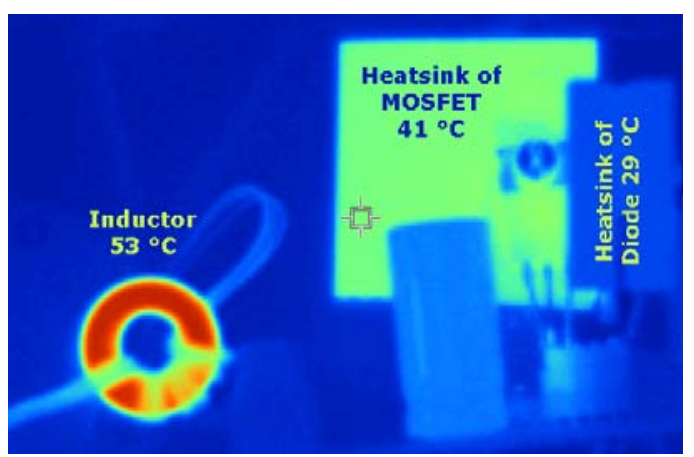

Fig.7. Thermal image of inductor $\left(53^{\circ} \mathrm{C}\right)$, diode $\left(29^{\circ} \mathrm{C}\right)$ and transistor $\left(41^{\circ} \mathrm{C}\right)$ in $\mathrm{DCM}\left(\mathrm{D} \approx 100 \%, \mathrm{I}_{\mathrm{LED}}=2.7 \mathrm{~A}\right.$, inductor core $\left.\mathrm{T} 60-26\right)$.
TABLE IV

Measured Distribution of Power Losses of Buck CONVERTER IN CCM AND DCM

\begin{tabular}{|c|c|c|c|c|c|c|c|c|}
\hline \multirow{2}{*}{$\begin{array}{c}I_{\text {out }}, \\
\%\end{array}$} & \multirow{2}{*}{$\begin{array}{c}\Delta \mathbf{P}_{\text {total }}, \\
\mathbf{W}\end{array}$} & \multirow[b]{2}{*}{$\eta, \%$} & \multicolumn{2}{|c|}{ Transistor } & \multicolumn{2}{|c|}{ Diode } & \multicolumn{2}{|c|}{ Inductor } \\
\hline & & & $\begin{array}{c}\Delta \mathrm{T}, \\
{ }^{\circ} \mathbf{C}\end{array}$ & $\begin{array}{c}\Delta \mathbf{P}, \\
\mathbf{W}\end{array}$ & $\Delta \mathbf{T},{ }^{\circ} \mathbf{C}$ & $\Delta \mathbf{P}, \mathbf{W}$ & $\begin{array}{l}\Delta \mathrm{T}, \\
{ }^{\circ} \mathrm{C}\end{array}$ & $\Delta \mathbf{P}, \mathbf{W}$ \\
\hline \multicolumn{9}{|c|}{ Pure CCM, L = 250uH, Inductor Core Material Mix 26} \\
\hline 33 & 0.4 & 91.6 & 6 & 0.2 & 9 & 0.3 & 8 & 0.2 \\
\hline 67 & 0.9 & 94.1 & 8 & 0.2 & 11 & 0.4 & 11 & 0.2 \\
\hline 100 & 1.7 & 95.9 & 12 & 0.4 & 12 & 0.4 & 15 & 0.4 \\
\hline \multicolumn{9}{|c|}{ Pure DCM, L = 2uH, Inductor Core Material Mix 26} \\
\hline 33 & 1.8 & 91.6 & 9 & 0.3 & 4 & 0.1 & 29 & 0.9 \\
\hline 67 & 2.6 & 94.1 & 16 & 0.6 & 7 & 0.2 & 36 & 1.2 \\
\hline 100 & 2.8 & 95.9 & 19 & 0.8 & 7 & 0.2 & 31 & 1.0 \\
\hline \multicolumn{9}{|c|}{ Pure DCM, L = 2uH, Inductor Core Material Mix 1} \\
\hline 33 & 1.1 & 94.8 & 11 & 0.4 & 5 & 0.1 & 9 & 0.3 \\
\hline 67 & 1.9 & 95.8 & 17 & 0.7 & 6 & 0.2 & 11 & 0.4 \\
\hline 100 & 2.2 & 96.8 & 19 & 0.8 & 6 & 0.2 & 10 & 0.3 \\
\hline
\end{tabular}

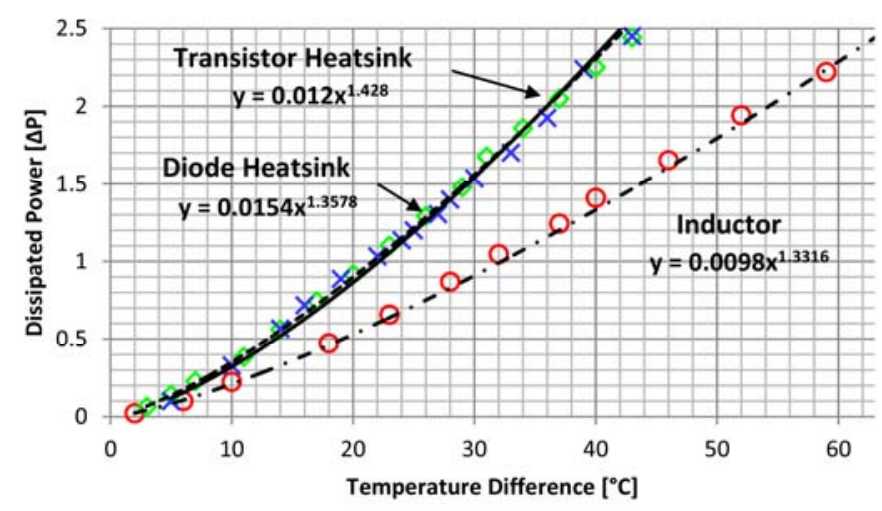

Fig.8. Relationships between the power dissipation in components and their temperature.

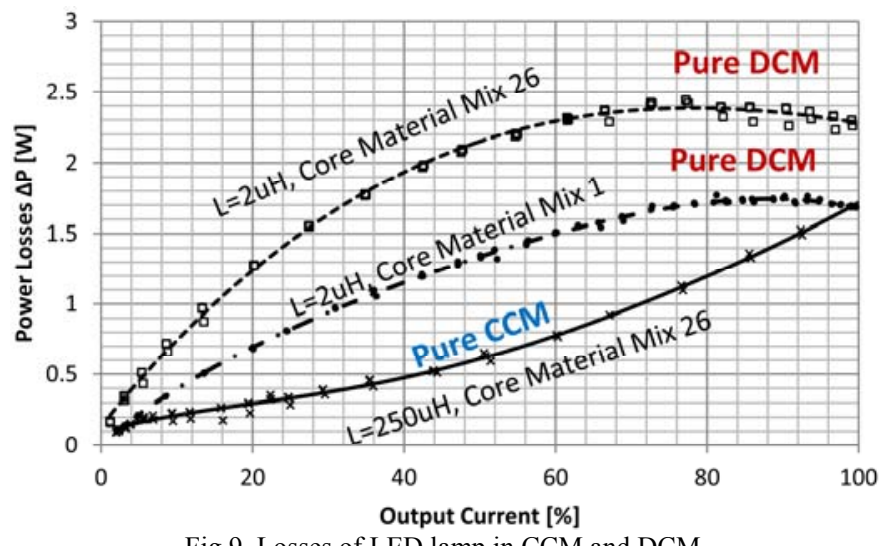

Fig.9. Losses of LED lamp in CCM and DCM. 


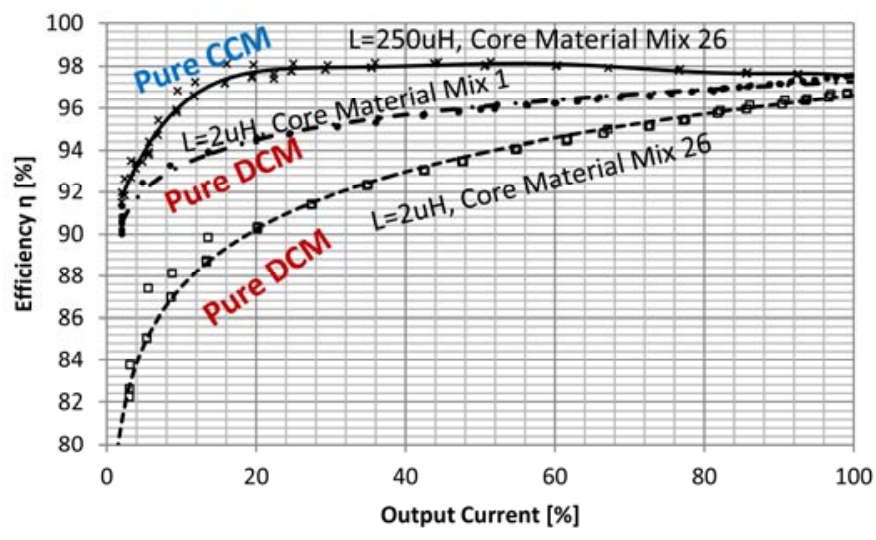

Fig.10. Efficiency of LED lamp in CCM and DCM.

Also the nonlinearity in DCM is slightly smaller than in CCM. Based on these conclusions it can be summarized that from the point of controllability the DCM is preferable. However, entering the DCM needs careful choice of the value of the inductor. To sum up, the losses are high, but it is possible to reduce them by the optimization of the inductor and output capacitor. At the same time, the size of the converter is smaller due to the smaller size of the inductor. Finally, taking into account all pros and cons, DCM can be carefully recommended for use in LED lamps.

\section{REFERENCES}

[1] Suzdalenko, A.; Galkin, I., "Investigation of power supply methods for intelligent LED luminary," Power Electronics and Motion Control Conference (EPE/PEMC), 2010 14th International, vol., no., pp.T666,T6-69, 6-8 Sept. 2010

[2] Apse-Apsitis, P.; Avotins, A.; Ribickis, L., "Wirelessly controlled led lighting system," Energy Conference and Exhibition (ENERGYCON), 2012 IEEE International, vol., no., pp.952,956, 9-12 Sept. 2012

[3] Seoul Semiconductor, W724C0 - datasheet, 2008, available electronically at www.seoulsemicon.com, last checked on August 13, 2010.

[4] Schmid, M.; Kuebrich, D.; Weiland, M.; Duerbaum, T.; , "Evaluation on the Efficiency of Power LEDs Driven with Currents Typical to Switch Mode Power Supplies," Industry Applications Conference, 2007. 42nd IAS Annual Meeting. Conference Record of the 2007 IEEE, vol., no., pp.1135-1140, 23-27 Sept. 2007

[5] Suzdalenko, A.; Galkin, I.; , "Choice of power and control hardware for smart LED luminary," Electronics Conference (BEC), 2010 12th Biennial Baltic, vol., no., pp.331-334, 4-6 Oct. 2010

[6] van der Broeck, Heinz; Sauerlander, Georg; Wendt, Matthias; , "Power driver topologies and control schemes for LEDs," Applied Power Electronics Conference, APEC 2007 - Twenty Second Annual IEEE, vol., no., pp.1319-1325, Feb. 25 2007-March 12007

[7] de Britto, J.R.; Demian, A.E.; de Freitas, L.C.; Farias, V.J.; Coelho, E.A.A.; Vieira, J.B.; , "A proposal of Led Lamp Driver for universal input using Cuk converter," Power Electronics Specialists Conference, 2008. PESC 2008. IEEE, vol., no., pp.2640-2644, 15-19 June 2008

[8] Tzuen-Lih Chern; Tsung-Mou Huang; Wen-Yuen Wu; Whei-Min Lin; Guan-Shyong Hwang; , "Design of LED driver circuits with single-stage PFC in CCM and DCM," Industrial Electronics and Applications (ICIEA), 2011 6th IEEE Conference on , vol., no., pp.2358-2363, 21-23 June 2011

[9] Alonso, J.M.; Gacio, D.; Garcia, J.; Rico-Secades, M.; Dalla Costa, M.A.; , "Analysis and design of the integrated double buck-boost converter operating in full DCM for LED lighting applications," IECON
2011 - 37th Annual Conference on IEEE Industrial Electronics Society, vol., no., pp.2889-2894, 7-10 Nov. 2011

[10] Galkin, I.; Milashevski, I.; Teteryonok, O.; , "Comparative study of steady-state performance of LED drivers at different modulation techniques," Compatibility and Power Electronics (CPE), 2011 7th International Conference-Workshop , vol., no., pp.382-387, 1-3 June 2011

[11] Galkin, I.; Teteryonok, O.; Milashevski, I.; , "Comparative estimation of efficiency of LED dimmers at different modulation techniques," Power Electronics and Applications (EPE 2011), Proceedings of the 2011-14th European Conference on, vol., no., pp.1-9, Aug. 30 2011-Sept. 12011

[12] Milashevski I., Tetervenok O., Galkin I. "Assessment of Energy Efficient LED Ballasts Based on Their Weight and Size" // Scientific Journal of RTU. 4. series., Power and Electrical Engineering. - 29. vol. (2011), pp 105-112.

[13] Ned Mohan, Tore M. Undeland, William P. Robbins, Power Electronics: Converters, Applications, and Design. Wiley, 2003, pp.164172

[14] R. W. Erickson, D. Maksimovic, Fundamentals of Power Electronics, 2nd Ed. Springer, 2001, pp. 107-139.

[15] M. Brown, Power Supply Cookbook, Second Edition. Boston: Newnes, 2001, pp. 232-236.

[16] Micrometals. Power Conversion and Line Filter Applications application note, issue L, 2007, available electronically at http://www.micrometals.com

[17] T. Einchhorn, Estimate Inductor Losses Easily in Power Supply Designs. Power Electronics Technology magazine, April 2005 Issue

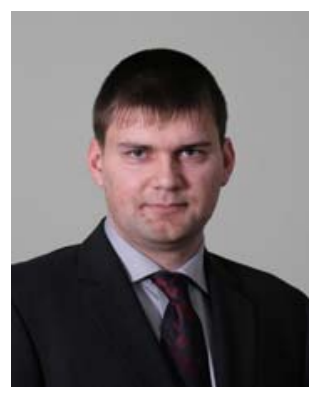

Olegs Tetervenoks received his Bachelor's Degree with Engineer qualification (2010) and Master's (2011) Degree in the field of electrical engineering at Riga Technical University, Faculty of Power and Electrical Engineering. Since 2011 he has been studying for his $\mathrm{PhD}$ at Riga Technical University. The Bachelor thesis was focused on solid state lighting technology development, in particular, on efficient LED power supply development. The Master thesis was devoted to LED light source efficiency evaluation equipment. The area of scientific interests of Olegs Tetervenoks covers microprocessor control systems and LED lighting technologies.

The working experience of Olegs Tetervenoks includes 2 years of research job at Riga Technical University.

Olegs Tetervenoks is IEEE member since 2011

e-mail: olegs.tetervenoks@rtu.lv

Postal address: Institute of Industrial Electronics and Electrical Engineering, Riga Technical University, Kronvalda boulevard 1, Riga LV1010, Latvia.

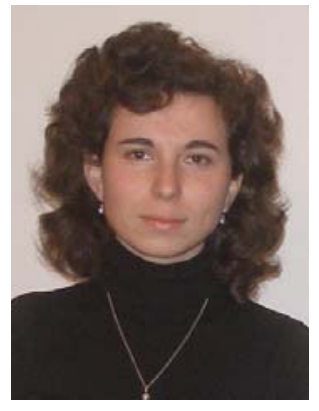

Irena Milashevski received her B.Sc. degree in Electrical Drives and Power Electronics in 2006 and M.Sc. degree in the same field in 2008 in Tallinn University of Technology. Since 2008 she has been studing for her PhD at Tallinn University of Technology (the thesis has been presented and degree - received in January 2013)

From 2006 she has working in electrical engineering company $\mathrm{KH}$ Energia-Konsult Plc as electrical designer and consulter. Her research interests include LEDs and their electronics ballasts energy efficiency, quality and economical problems in the lighting field.

e-mail: renamilashevski@gmail.com

Postal address: Department of Electrical Engineering, Tallinn University of Technology, Ehitajate tee 5, 19086 Tallinn, Estonia. 